\title{
Behavioural Change \& Exercise: How to stop people from quitting
}

Line Smith \& Lisa Monge

\section{Introduction}

Physical activity plays a significant part in staying healthy. A healthier, more physically active lifestyle leads to a diminished chance of succumbing to a variety of diseases that endanger the lives of millions across the world. One of the most wellknown of these diseases is obesity, discussed in the paper by Campisano and Stewart (2008). That paper suggests taxes and tariffs on trans, saturated fats and sugars to diminish the problem.

While obesity is truly an endemic problem, we begin our paper on the established premise that physical activity is critical in preventing such diseases. We believe that the question of how obesity can be avoided by adopting a physically active lifestyle is as important as the issue that motivates our paper - that of how to stop people from quitting.

The purpose of this report is to examine the reasons for why the rates for physical activity are so low and to provide a discussion of the possible initiatives that would prevent people from quitting once they have started exercising.

\section{An Analysis of the Market Structure}

The Suppliers

The market for structured exercise can be described as being monopolistically competitive market as there are numerous participants offering differentiated 
products and consumers develop a degree of loyalty to the brand and features each provides. It is a dynamic market with new gyms regularly opening, new group fitness classes being initiated, personal training expanding, gym equipment constantly being developed and parks, paths and government-supported programs regularly being introduced. In addition, due to the greater value the general public places on being fit and healthy, the demand for fitness facilities and equipment is likely to increase (IBISWorld 2011). There is therefore room for innovative competition in this market.

The Consumers in Australia

When it comes to Australia's current exercise behaviours there are some very revealing statistics that deserve attention. While $10 \%$ of the Australian population have gym memberships only $10 \%$ of these people actually use them. In addition, $50 \%$ of new gym members 'drop out' of their gym programs in the first month (Australian Institute of Fitness 2011). Moreover, while it is now commonly realized that most adults should participate in a minimum of 30 minutes of moderate physical activity a minimum of five days per week only $28 \%$ of the population actually do so.

According to Goldhaber-Fiebert (2011), failure to exercise is not due to ignorance but stems from difficulties in translating initial motivation into sustained behavioural change. Studies also show that a key reason for not exercising is a lack of time. Other reasons are difficulties to commit, pain, no motivation, kids and family, a lack of knowledge or a lack of results (Australian Institute of Fitness 2011). We now analyse the factors within a framework of economic theory that considers how a consumer's preference for physical activity can be related to behavioural issues. 


\section{The Economic Theory of Behavioural Change}

Three theories in particular offer particular insight for why commitments to exercise tend to be temporary. When asked, most of us claim that we want to be more active. The problem is converting current motivation into a permanent behavioural change that enables sustained outcomes. Our decision-making preferences change over time and setting a goal only to abandon it in the future is known as dynamic inconsistency (Goldhaber-Fiebert 2011). Hyperbolic discounting provides an explanation for this dynamic inconsistency by suggesting that consumers often discount future payoffs hyperbolically rather than exponentially. In other words they prefer rewards that arrive sooner rather than later. People discount the reward with a factor that increases with the length of the delay. This can justify the preference of even smaller rewards that accrue earlier in comparison with larger rewards that arrive later. (Ainslie \& Monterosso 2002). Agents therefore seem to abandon their exercise habit as they prefer an immediate award such as a chocolate bar rather than an hour at the gym providing them with future benefits.

The theory of bounded rationality sheds further light on the issue. A consumer's choice is assumed to be rational in the pursuit of utility maximization. However, due to limited and unreliable information, limited time and the limited capacity of the human mind to evaluate and process available information, individuals are bound to make satisfying rather than optimizing choices in certain situations (Stutzer 2007). We therefore end up having to making suboptimal decisions that could contradict our best interests.

The health and fitness industry keeps growing as does its supply of new innovative exercise options to provide for different needs. Whether these options are taken advantage of by a consumer, however, may also depend on socioeconomic factors. These include education, occupation, level of income, family situation, and their quality of living in the community. Depending on the alternatives and encouragement the community provides, an individual's level of activity may be 
influenced. The supply of choices available within the community and the individual's disposable income can restrict the exercise options available. When there are less desirable options, greater incentives are needed. Some individuals lack the education and knowledge, preventing them from quitting. This is due to an unawareness of the associated dangers of inactivity and a lack of confidence associated with inabilities to sustain habits. Occupation is also critical, influencing both time and income. In addition, having a family reduces the convenience of exercising and time with children may be seen as an opportunity cost leading to people breaking their exercise cycle. Motivation and effort can also depend on an individual's social circle. Being surrounded by inactive, less educated people might impart a negative externality on one's own behaviour.

Some individuals are nevertheless successful in making physical activity a habit. Whether individuals manage to form a habit or not depends on aspects such as opportunity cost, motivation and the cost of effort. The initial cost of effort associated with exercising is high, making individuals less likely to put in the effort. As the opportunity cost of exercise starts to increase, individuals are less likely to continue exercising due to their time and budget constraints. Interventions that might exacerbate the motivational factor may include personal training options, weight loss and positive image programs in the media and exercise tracing devices such as pulse watches and running monitors. On the other hand, the longer an individual maintains the effort and commitment to their exercise routine, the greater is the chance that behavioural change is going to be successful as they reap the benefits of exercise with increasing returns from effort (Garrouste \& Iōannidēs 2001). This can also be associated with path dependency, where individuals confronted with a decision are more likely to make the same decision as they have made in the past (Garrouste \& Iōannidēs 2001). Given that lethargy and physically active lifestyles are both path dependent, the conclusion must be that the switching 
costs from one to the other are high and therefore motivational interventions are as important to one group as they are to the other.

Higher utility is associated with a healthier and more physically active lifestyle, making it the rational choice for agents. However, consumers are at great risk of abandoning this lifestyle as the rewards associated with the choice are delayed or of the opportunity costs are insurmountable. As immediate satisfaction is valued higher than future satisfaction, committing to an exercise plan has a high probability of failure, the reason being the likelihood of the human brain to make satisfying rather than optimizing decisions. What is of great importance is to get people to see the benefits of making the choice of doing something less desirable today that will benefit them and others in the future. As the individual manages to make the initial change and overcome socioeconomic factors including limited education and low disposable income, commitment is more likely to be a success due to increasing returns from effort and the formation of a habit. This is above all more likely to be the case if the local community has various options available.

\section{Market Failure Analysis}

The effects of choices made by individual consumers on external parties are of significance. Obesity and other consequences resulting from not being physically active impose negative externalities on society such as increased public health expenditures. This is a result of a market failure brought about as a consumer's pure self-interest is leading to inefficient results. Arguably opportunity cost contributes to market failure and therefore interventions that make exercising more convenient and reduce the opportunity cost, making individuals less likely to quit, thus ameliorating the market failure as well.

A significant amount of public and private resources are spent on medical care expenditures due to inactivity. As private and public health insurance firms and governments cover a large percentage of these expenses it could be said that the 
population pays the bill instead of those who are not healthy as a result of inactivity due to inability of sticking to a habit. Obesity, as a result of lack of exercise, can also be contagious. If surrounding friends and family do not engage in physical activity or have recently given up, there are fewer incentives for certain individuals to keep exercising as well. Lack of mobility and energy may also have a negative impact on the economy, as individuals do not perform optimally and the economy loses productivity. In addition, those not engaging in enough exercise may end up having to claim on their health insurance more often, increasing premiums paid by healthy individuals who do exercise. Moreover, people who have previously experienced a failed attempt at changing to a more physically active lifestyle may have an even smaller chance of becoming healthy in the future due to path dependency. People that have experienced such disappointment and waste of effort are more likely to experience physiological frustration and develop problems such as eating disorders and depression.

\section{Suggested Interventions for Increased Market Efficiency}

Due to these negative externalities leading to market failure, an increased emphasis has been placed on various interventions to address the lack of physical activity. We would suggest a similar emphasis to also accompany maintaining a physically active and healthy lifestyle.

Zimmerman (2009) uses behavioural economics to suggest that social norms, habits or cultural frames are all factors influencing whether physical activity is fun or just hard work. Changing these anchor points may become useful in sustaining a positive attitude towards exercising. It has also been suggested that physical activity may increase if policy makers focus their attention on promoting family friendly exercise programs, due to the time pressure constraints parents are facing (Brown \& Roberts 2010). The Australian Institute of Fitness (2011) also states the importance of an early promotion of physical activity to young children. They argue 
that children need to learn fundamental skills and the ability to develop health related fitness, the argument being that the earlier you start forming people's habits, the more likely it is to become a natural part of their everyday life. Community-based physical activity interventions are proven to be a cost-effective way of promoting a more active lifestyle. These are interventions like improved access to facilities such as fitness centers, bike paths and walking trails. It is also important that town planners and governments stress the positive benefits of physical activity and help facilitate it (Brown \& Roberts 2010).

A more controversial intervention would be to introduce an obesity tax on overweight people couple with a reward for those that maintains a healthy lifestyle. Taxes and tariffs are seen on unhealthy products such as trans, saturated fats and sugars to diminish the problem. Increasing costs or penalties therefore seem to be an effective way of keeping people from eating unhealthy.

In keeping with our argument in this paper we think another intervention that could be considered would be increasing future awards to make future goals more desirable than the present. One such solution might be a reward of $\mathrm{X}$ after 2 years and then another reward of $X^{*} 2$ after 3 years and so on. Verifiability of results could be easily accomplished using the existing records of consumers within the medical system.

\section{A Concluding Thought}

Rational agents chose a healthier lifestyle by incorporating exercising into their life as they seek maximum utility. However, as rewards are delayed many abandon this rational way of thinking. The low rates of exercise and how to stop people from quitting have therefore been examined in this report. To conclude, interventions to increase market efficiency have been studied to reduce the cost of negative externalities imposed on the market. 


\section{References}

- Australian Institute of Fitness (2011) Gym Instructor, retrieved 20 April 2011,

- http://ecampus.nsw.fitness.edu.au/

- Ainslie, G and Monterosso, J (2002) "Hyperbolic discounting lets empathy be a motivated process", Behavioral \& Brain Sciences, Vol. 25 Issue 1, pp.20- 21

- Brown, H and Roberts, J (2010) "Exercising Choice: The Economic Determinants of Physical Activity Behavior", Department of Economics, Retrieved 15 April 2011, http://melbourneinstitute.com/downloads/hilda/Bibliography/wp/Brown_ Roberts_Exercising_Choice.pdf

- Stutzer, A (2007) "Limited self-control, obesity and the loss of happiness", University of Basel-Department of Business and Economics, retrieved 20 April 2011,

- http://papers.ssrn.com/sol3/papers.cfm?abstract_id=1001413

- Garrouste, P and Iōannidēs, S (2001) Evolution and path dependence in economic ideas: past and present, Edward Elgar Publishing Inc, Massachusetts.

- Goldhaber-Fiebert, JD and Garber, AM (2011) "The Behavioral economics of exercise habits", VOX, Retrieved 20 March 2011,

- http://www.voxeu.org/index.php?q=node/6142 
- IBISWorld (2011) "Gyms, Sports Grounds, and Other Facilities in Australia", Retrieved 12 April 2011, http://www.ibisworld.com.au/industry/default.aspx?indid=658

- Zimmerman, FJ (2009) "Using behavioural economics to promote physical activity", Department of Health Services, retrieved 13 April 2011,

- http://www.activelivingresearch.org/files/5_PM2009_Zimmerman.pdf 